\title{
Temporal lobe epilepsy due to an intracerebral Schwannoma: case report
}

\author{
M. J. VAN RENSBURG, N. S. F. PROCTOR, J. DANZIGER, \\ AND M. S. ORELOWITZ \\ From the Department of Neurosurgery of the Johannesburg Hospital \\ and the South African Institute for Medical Research, Johannesburg, South Africa
}

SYNOPSIS An intracerebral Schwannoma giving rise to temporal lobe epilepsy is described. The possible origin of such tumours in the central nervous system in general, and in the temporal lobe in particular, is discussed.

Isolated Schwannomas form about $8 \%$ of all primary intracranial tumours, usually occur during the middle years of life, and are about twice as common in females as in males (Minckler, 1971; Russell et al., 1971). They are extremely rare in childhood (Matson, 1969) and, as in adults, the acoustic nerve is the site of predilection (Craig et al., 1954). Even if patients with von Recklinghausen's disease be included, Schwannomas constitute only $0.3 \%$ of childhood intracranial neoplasms (Koos and Miller, 1971).

Parenchymatous Schwannomas of the brain and spinal cord are rare lesions. Intramedullary tumours of the spinal cord have gained mention in standard reference works (Minckler, 1971; Russell et al., 1971) but by 1964 McCormick was able to report only the ninth recorded case. The only reference to an intracerebral Schwannoma that we could find in a standard textbook is that of Scharenberg (1971) who, in discussing Schwannomas of the eighth cranial nerve in neurofibromatosis, mentions, obliquely and in parentheses, that such a patient with bilateral acoustic tumours also harboured a Schwannoma in the right occipital lobe, as well as bilateral third nerve tumours. The intracerebral tumour is not described in any way and judgement on its lineage must be reserved, particularly in view of a statement in the final paragraph of his chapter where he says that the Schwannoma of von Recklinghausen's disease might be regarded

(Accepted 17 February 1975.) as a peripheral glioma closely related to those of the brain.

As far as we are aware, there have been only two previous documented reports of intracerebral Schwannomas. In 1966 Gibson et al. published what appears to have been the first report, and in 1972 New reported a second case. This report describes a temporal lobe tumour with the features of a Schwannoma in a 21 year old white man who had shown symptoms of its presence since the age of 14 years.

\section{CASE REPORT}

The patient was a 21 year old unmarried white male who complained of episodes of uncontrollable behaviour of which he subsequently had no recollection. Birth had been normal and there were no infantile convulsions or any significant previous illnesses. Seven years previously, at the age of 14 years, he started experiencing attacks two or three times daily in which he felt light-headed and compulsively rubbed his hands and arms against each other. About two years before the present admission the attacks changed in character. The episodes now commenced with a feeling of intense and indefinable pleasure, after which he had no further recollection of what happened until 10 or 15 minutes later when he again became aware of his surroundings. During the period of amnesia he was told that he became uncontrollable and did strange things, becoming uncharacteristically violent at times. Normally a mild-mannered man he assaulted a patient in the bed next to him during his admission, and a fully703 

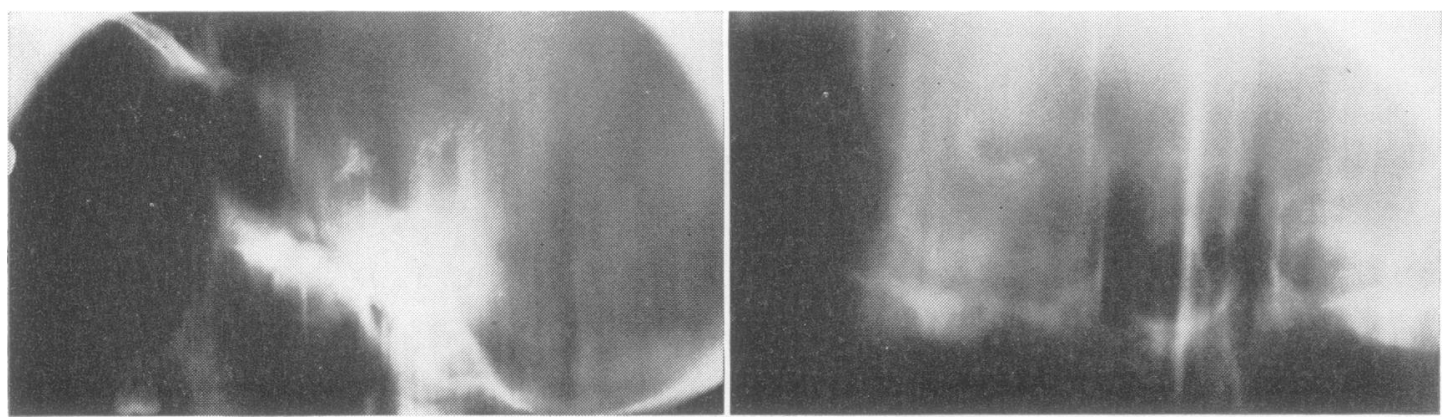

FIG. 1 (left) Lateral tomogram of the calcification in the middle fossa. FIG. 2 (right) Anteroposterior tomogram of the calcification.
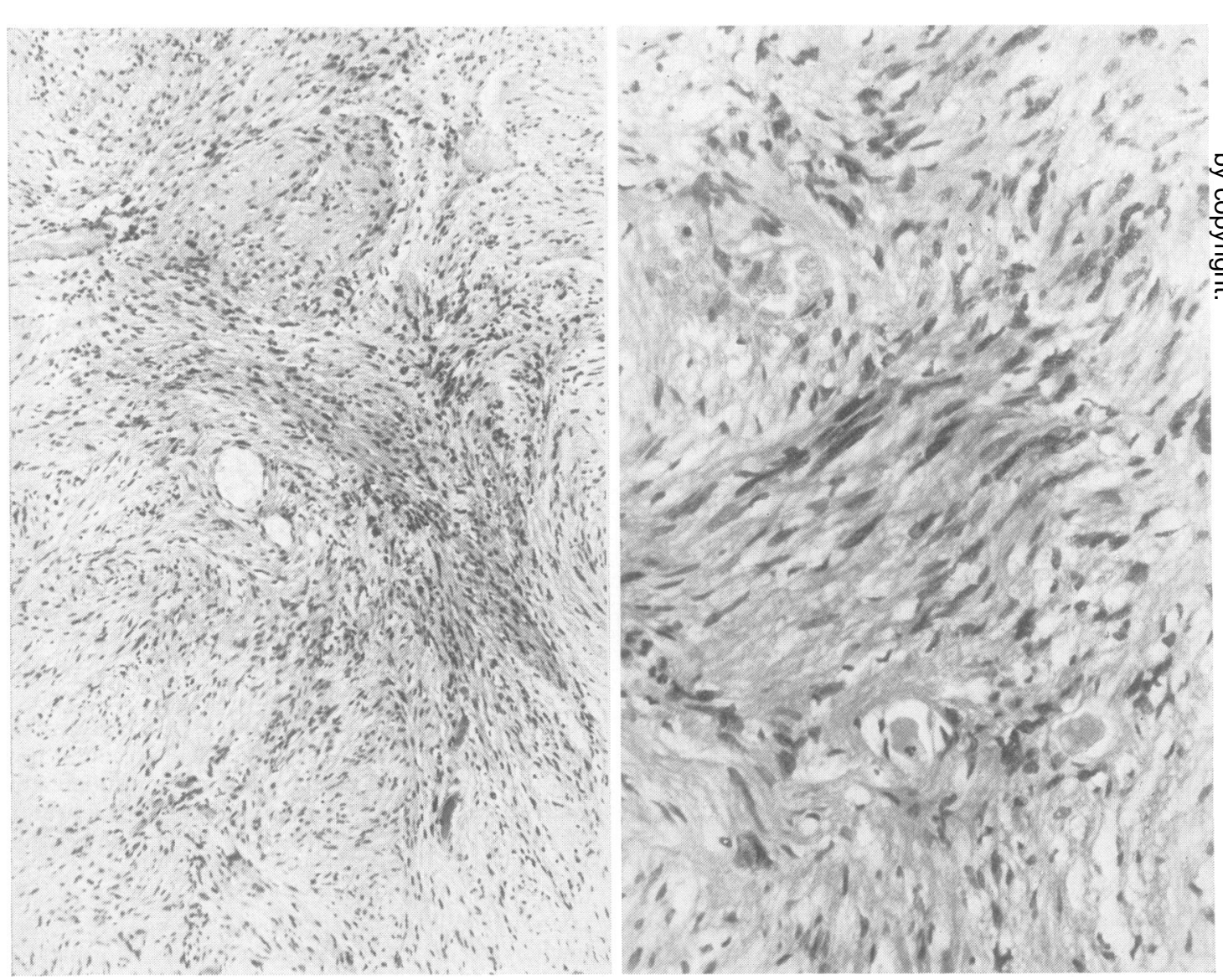

FIG. 3 (left) The histological appearance of the tumour showing predominant spindle cell structure. $H$ and $E$, $\times 70$. FIG. 4 (right) Higher power showing a tendency to palisading of the nuclei. $H$ and $E, \times 180$. 
which he ran about the ward in obvious terror, violently objecting to restraint, and finally cowered on the floor shouting 'No, no, no!'. His only other complaint was of frequent headaches for many years in the temples and behind the eyes.

A diagnosis of temporal lobe epilepsy had been made soon after the onset of the illness, but there had been a poor response to intensive and varied anticonvulsant therapy. Periods of freedom from attacks lasting up to three months had occurred, but these were followed by periods of many weeks during which he might experience up to seven attacks a day. His employer had recently postponed his demotion from a supervisory post to see if anything could be done for him. He also showed considerable concern about his social future and felt that he could not possibly risk marriage, more especially as sexual arousal seemed to precipitate attacks.

There were no physical abnormalities on clinical examination and he was neurologically intact. In particular, there were no stigmata of von Recklinghausen's disease and no family history of this disorder. Routine blood examinations and a glucose tolerance curve were normal and the Wassermann reaction negative. Lumbar puncture revealed the cerebrospinal fluid to be at normal pressure and the analysis was normal with no cells and a protein content of $0.31 \mathrm{~g} / \mathrm{l}$.

The electroencephalogram was mildly dysrhythmic with an excess of low voltage theta activity occurring in all leads. There was no focal abnormality and no episodic discharge. A sedation record was no more
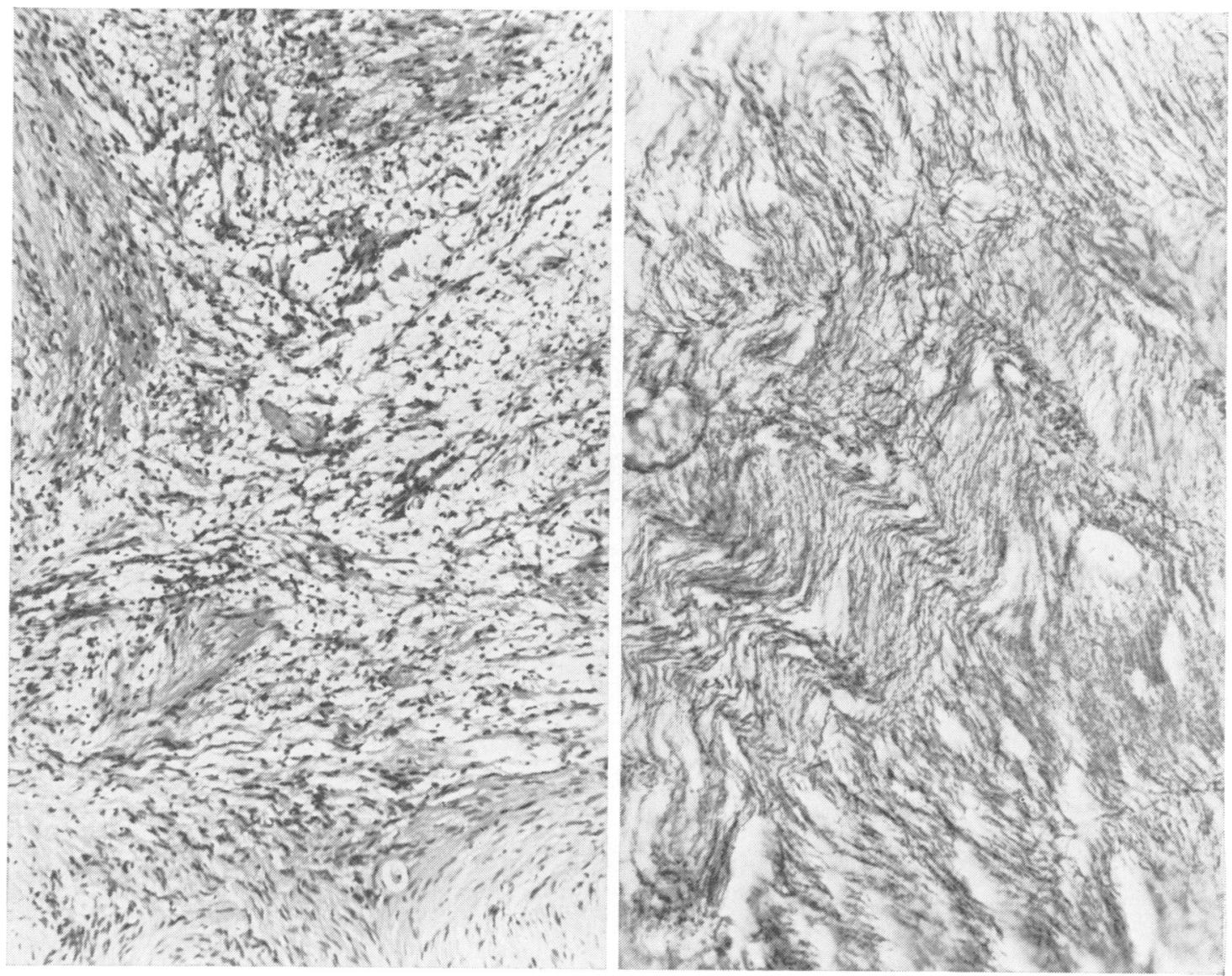

FIG. 5 (left) A portion of the neoplasm showing variation in structure presenting solid and loose stromal areas. $H$ and $E, \times 70$. FIG. 6 (right) The dense reticulin network seen in the solid parts of the tumour. Reticulin stain, $\times 280$. 
informative, but with activation by bemegride (Megimide) the record became increasingly abnormal with increments of dosage, culminating in a build up of $2-3 \mathrm{~Hz}$ activity in the right temporal region and with high voltage right frontotemporal spikes. The recording was abruptly terminated by the occurrence of a temporal lobe seizure.

Radiographs of the skull showed an area of calcification in the right temporal region and enlargement of the right middle fossa was noted retrospectively. Tomography confirmed the presence of a well-defined area of irregular calcification in the middle fossa, $4.5 \mathrm{~cm}$ posterior to the anterior wall and $2.5 \mathrm{~cm}$ lateral to the pituitary fossa (Figs 1 and 2). Pneumoencephalography showed slight rounding of the superolateral angles of the lateral ventricles, but no evidence of a mass in relation to the right tem- poral horn which was not displaced. Air seemed to cap the area of calcification, suggesting that the latter lay in the pes hippocampi. Right carotid angiography with crossover studies demonstrated asymmetry of the middle cerebral arteries, the knee of the right middle cerebral artery being displaced medially. No tumour circulation was demonstrated and it was thought that the asymmetry could just be within normal limits.

Thus, contrast studies did not unequivocally demonstrate a significant mass lesion, and the favoured diagnosis was a calcified hamartoma.

OPERATION AND POSTOPERATIVE COURSE It was decided to perform a formal temporal lobectomy, as this was thought to offer the greatest prospect of removal of epileptogenic brain should the lesion
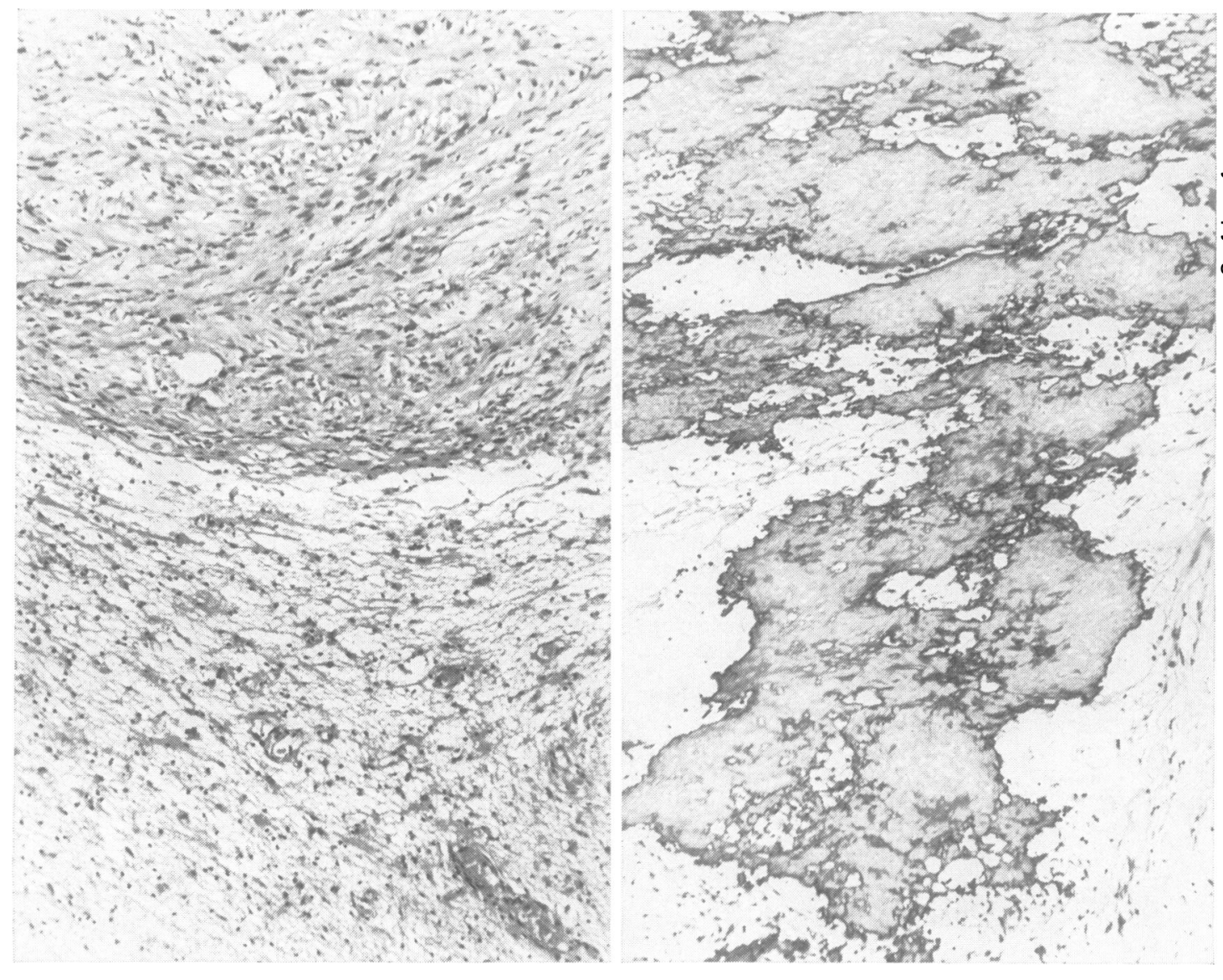

FIG. 7 (left) The edge of the tumour showing, at the bottom, glial proliferation around the neoplasm. PTAH, $\times 70$. FIG. 8 (right) Dense calcification seen mainly round the periphery of the tumour. $H$ and $E, \times 70$. 
prove to be benign, and it also seemed to be the most logical procedure for the resection of a possible glioma. Through a right frontotemporal osteoplastic flap an en bloc removal of the anterior $6 \mathrm{~cm}$ of the temporal lobe, with sparing of the superior temporal gyrus, was embarked on (Walker, 1967). There were no obvious surface abnormalities but the cerebral incisions passed through yellowish, tough, macroscopically gliosed white matter. On opening the temporal horn, a reddish nodular mass flecked with grey, and gritty to the touch of a blunt dissector, was seen to protrude slightly into the ventricle in the expected position of the bulge of the amygdaloid nucleus. It was decided to remove the mass before proceeding with the lobectomy as it would have hampered dissection in the region of the uncus. Removal was easy as it was nowhere in contact with meninges and was surrounded on all fronts with brain tissue except posteriorly where it protruded into the temporal horn, and anteriorly where it lay in contact with a cyst containing about $30 \mathrm{ml}$ of clear, yellow fluid. It was entirely separate from the choroid plexus. It was $2 \mathrm{~cm}$ in diameter and its whole surface was similar to that portion protruding into the ventricle. On frozen section it was thought to be either a fibrous meningioma or a Schwannoma. The postoperative course was uneventful and at the time of writing, 21 months later, he has not experienced a further seizure, does not suffer from headaches, and is neurologically intact apart from a left superior homonymous quadrantanopia.

PATHOLOGICAL EXAMINATION The tumour was firm and on section spicules of calcification were evident. Histological sections showed the tumour mass to consist of interweaving bundles of spindle cells which in many areas showed nuclear palisading, and a dense collagenous stroma (Figs 3 and 4). The spindle-shaped nuclei had the features of Schwann cells with blunt ends and lacked any evidence of whorling which might suggest a meningioma. There was no evidence of mitotic activity and the neoplastic cells were well differentiated. Areas of degeneration were present in the neoplasm and in certain areas loose stromal tissue suggested foci of Antoni type II tissue in the main mass of Antoni type I structure (Fig. 5). Abundant reticulin formation within the tumour was demonstrated by appropriate staining methods (Fig. 6). The tumour was surrounded by dense glial tissue which extended far into the surrounding brain and which also penetrated the neoplasm at various points (Fig. 7). Extensive calcification was present in the surrounding brain and there was also calcification within the tumour, confirming the macroscopic findings (Fig. 8). The histological features thus demonstrated the characteristics of a Schwannoma situated in an intracerebral position.

\section{DISCUSSION}

The Schwannoma reported by Gibson et al. (1966) was removed from the superior portion of the mid-temporal lobe of a 6 year old boy, while New (1972) reported a similar tumour removed from the superior parietal lobule of an 8 year old boy. In neither case does there appear to have been evidence of neurofibromatosis.

In view of the rarity of solitary Schwann cell tumours in childhood, and their lower incidence in males, it is interesting that the three reported intracerebral tumours all occurred in young males.

That the cerebral arteries are accompanied by perivascular nerve plexuses has been abundantly demonstrated, and cerebral arterioles down to 10 or $15 \mu \mathrm{m}$ receive an adrenergic supply (Purves, 1972). As long ago as 1932 Penfield demonstrated the presence of Schwann cells in these nerves. However, the rarity of intracerebral Schwann cell tumours would seem to warrant the quest for factors additional to the mere presence of these cells.

When lesions uncharacteristically occur in the young, the possibility of developmental causes is naturally entertained. With reference to spinal intramedullary Schwannomas, Ramamurthi et al. (1958) suggested on hypothetical grounds that displaced neural crest cells may be the source of the tumours, and they postulated that such cells may possess an increased neoplastic potential.

In about one quarter of temporal lobes resected for temporal lobe epilepsy foci of abnormal tissue are found, varying from a few millimetres to one or two centimetres in diameter (Corsellis, 1970). They are usually glial, but may be mainly vascular, and in a small number there is only a subtle disorganization of cortical histological structure by abnormal glial cells and neurones. Similar lesions appear to be only rarely the cause of focal seizures elsewhere in the brain (Penfield and Jasper, 1954; Corsellis, 1970). It thus appears that anatomical disorganization is either more common in the temporal lobe, or more easily gives rise to focal epilepsy in that situation. We wonder if abnormal 
development of this type may also embrace the Schwann cells as well as the glia, neurones, and blood vessels. Cavanagh (1958) considered the possibility that these glial and neuronal hamartomatous malformations may form a nidus for the development of gliomas, and it would seem reasonable to postulate that hyperplastic Schwann cells could similarly evolve into tumours. The considerable weakness of this argument is, of course, that hyperplastic Schwann cells have not to our knowledge been identified in the cerebral hemispheres. But then intracerebral Schwann cell tumours are also very rare indeed.

Aberrant peripheral nerve fibres have been found in the medulla oblongata as a chance finding on serial section (Demyer, 1965). They arose from the vagal rootlets and bilaterally and symmetrically penetrated the medulla, some in company with blood vessels. None of the three reported tumours has, however, been even remotely related to the attachment of a cranial nerve.

The origin of Schwann cells giving rise to intramedullary spinal cord tumours has been speculated on by all the workers reporting these neoplasms (Kernohan, 1941; Riggs and Clary, 1957; Ramamurthi et al., 1958; McCormick, 1964). The autonomic perivascular nerve plexuses of the spinal cord are thought by most to be the likely origin of these tumours, but Schwann cells may also be found in the region of the posterior horn, usually in relation to a Schwannoma on the entering root (Russell et al., 1971). A tumour occupying this region of the spinal cord has been reported (McCormick, 1964). Riggs and Clary (1957) have shown that hyperplasia of the perivascular nerve plexuses of the spinal cord is particularly likely to occur in the presence of chronic diseases of the cord and in older patients. They, however, felt that developmental dysplasia could not entirely be dismissed and in three of the 36 spinal cords they examined there were manifestations of defective embryonic growth. They concluded that both developmental and pathological processes may contribute to the hyperplastic cells. In our patient there was extensive gliosis of the temporal lobe, and the marked gliosis at a distance from the growth appeared rather excessive to be a secondary effect of the tumour. It is interesting to speculate whether a hyperplastic perivascular nerve plexus may have been present in an abnormal temporal lobe as a precursor to the tumour. The temporal lobe was unfortunately discarded by the laboratory before it could be established if the classical features of incisural sclerosis were present and before a wider search could be made for hyperplastic foci of Schwann cells.

In an attempt to explain the ensheathment of myelinated fibres of the central nervous system with Schwann cells, as may occur when there is pathological incorporation of connective tissue in the brain, Russell et al. (1971) have on morphological grounds suggested that pial cells may undergo this conversion. Conceivably, such cells may give rise to a Schwann cell tumour. In our case there was no reason to suspect that this may have occurred, as adipose tissue or other connective tissue was not identified in relation to the tumour.

\section{REFERENCES}

Cavanagh, J. B. (1958). On certain small tumours encountered in the temporal lobe. Brain, 81, 389-405.

Corsellis, J. A. N. (1970). The neuropathology of temporal lobe epilepsy. In Modern Trends in Neurology, vol. 5, pp. 254-270. Edited by D. Williams. Butterworths: London.

Craig, W. McK., Dodge, H. W., Jr, and Ross, P. J. (1954). Acoustic neuromas in children. Report of 2 cases. Journal of Neurosurgery, 11, 505-508.

Demyer, W. (1965). Aberrant peripheral nerve fibres in the medulla oblongata of man. Journal of Neurology, Neurosurgery, and Psychiatry, 28, 121-123.

Gibson, A. A. M., Hendrick, E. B., and Cohen, P. E. (1966). Intracerebral Schwannoma. Report of a case. Journal of Neurosurgery, 24, 552-557.

Kernohan, J. W. (1941). Tumors of the spinal cord. Archives of Pathology, 32, 843-883.

Koos, W. T., and Miller, M. H. (1971). Intracranial Tumors of Infants and Children. Thieme: Stuttgart.

McCormick, W. F. (1964). Intramedullary spinal cord Schwannoma. A unique case. Archives of Pathology, 77, 378-382.

Matson, D. D. (1969). Neurosurgery of Infancy and Childhood, 2nd edn. Thomas: Springfield, Ill.

Minckler, J. (1971). Supporting cell tumors of peripheral nerves. In Pathology of the Nervous System, vol. 2, pp. 2093-2114. Edited by J. Minckler. McGraw-Hill: New York.

New, P. F. J. (1972). Intracerebral schwannoma. Case report. Journal of Neurosurgery, 36, 795-797.

Penfield, W. (1932). Intracerebral vascular nerves. Archives of Neurology and Psychiatry (Chic.), 27, 30-44.

Penfield, W. G., and Jasper, H. H. (1954). Epilepsy and the Functional Anatomy of the Human Brain. Churchill: London.

Purves, M. J. (1972). The Physiology of the Cerebral Circulation. Cambridge University Press: London. 
Ramamurthi, B., Anguli, V. C., and Iyer, C. G. S. (1958). A case of intramedullary neurinoma. Journal of Neurology, Neurosurgery, and Psychiatry, 21, 92-94.

Riggs, H. E., and Clary, W. U. (1957). A case of intramedullary sheath cell tumor of the spinal cord. Consideration of vascular nerves as a source of origin. Journal of Neuropathology and Experimental Neurology, 16, 332-336.

Russell, D. S., Rubinstein, L. J., and Lumsden, C. E. (1971).
Pathology of Tumours of the Nervous System, 3rd edn. Arnold: London.

Scharenberg, K. (1971). Neurofibromatosis (von Recklinghausen's disease). In Pathology of the Nervous System, vol. 2, pp. 1906-1916. Edited by J. Minckler. McGrawHill: New York.

Walker, A. E. (1967). Temporal lobectomy. Journal of Neurosurgery, 26, 642-649. 